\title{
An Analyses of Threats to the Realisation of the United Nations' Sustainable Development Goals Report 2019 in the Light of the Recent Report of the Global Futures (ie The World Wildlife Fund) on the Unfolding Trends on the Environment in Nigeria and the Globe - A Call for Sustained Global Action
}

\author{
Dr. Sylvanus Abila, Ph.D \\ Senior Lecturer/Former Head of Department, Private and Property Law, Faculty of Law Niger Delta University, \\ Wilberforce Island, Bayelsa State, Nigeria
}

\begin{abstract}
The paper analyses the threats to the realization of the United Nations' sustainable development goals report 2019 in the light of the recent report of the global futures (i.e The World Wildlife Fund) on the unfolding trends on the world's environmental conditions in Nigeria/the globe and calls for sustained global action. In achieving its purpose, this paper referred to the United Nations Sustainable Development Goals Report 2019 and the recent updates from the World Wild Life Fund (WWF) and concludes that the world must move fast to implement the goals contained in the United Nations Sustainable Development Goals Report 2019 to avoid catastrophic impacts in annual global losses from flooding, storms, ocean surges and erosions due to changes in vegetation along coastlines and sea-level rises, loss of carbon storage, climatic changes etc. The paper ends with a conclusion and set of recommendations.
\end{abstract}

Keywords: Analyses, Threats, Realisation, Sustainable Development Goals, Global Futures, Unfolding Trends, the Environment, Sustained Global Action.

DOI: $10.7176 /$ JLPG/95-06

Publication date:March $31^{\text {st }} 2020$

\section{Background}

It is a well-known fact that the United Nations' Sustainable Development Goals (SDGs), are known to address fundamental matters in the reduction of poverty and generally brings about sustaining development in to globe. It is a moot point that, virtually in all nations of the world, issues dealing with development have, have being promoted, persistently by the United Nations system. One major was on the proclamation and adoption of the Millennium Development Goals, MDGs, between the years 2000 - 2015. The MDGs, were eight in number and targeted to eliminate poverty and hunger in their extreme manifestations. Other goals were targeted to achieve universal primary education, combat HIV/AIDS, reduce child mortality, improve maternal health, promote gender equality. Others included the elimination of malaria, other diseases and also bringing about environmental sustainability etc. This goals were meant to be applied around the globe. ${ }^{1 a}$

In Nigeria, "a review of its performance in the attainment of the MDGs concluded that Nigeria did not attain the MDG targets by the end of 2015, though smaller African nations such as Ghana, Cameroun and Botswana performed far better and substantially met the goals. It is a sad commentary on governance system that most other African countries, including Nigeria, failed to meet any of the gargets". ${ }^{2 b}$ According to some estimates at about the end of the MDG period, "Nigeria had an infant mortality rate of 72.7 deaths/1,000 live births, a contraceptive prevalence of $15.1 \%$, health expenditure of about $4 \%$ of GDP, HIV prevalence of $3.17 \%$, a HIV burden of $3,228,600$ and HIV associated deaths of 174,3000, with life expectancy at birth of 53.02 years. These were not unexpected, as a multiplicity of health system-related, political and systemic challenges, among other factors worked against the attainment of the goals". ${ }^{2}$ Given the termination of the 15 year MDG period in 2015, a new United Nations development agenda, the 2030 Agenda for Sustainable Development or the Sustainable Development Goals (SDGs) for the period 2015-2030 was adopted. The SDGs being a successor programme to the Millennium Development Goals (MDGs) with a collection of 17 global goals and 169 targets was set to transform living standards worldwide. As a 15 year plan, which commenced on January 1, 2016, it is expected to end on December 31, 2030, covers social and economic development issues such as poverty, hunger health, education, global warming, gender equality, water, sanitation, energy, urbanization, environment and social justice, among others. ${ }^{3}$

\footnotetext{
la See The Guardian, Nigeria, Wednesday, March 13, 2019, P.18

$2 \mathrm{~b}$ Ibid.

2 Ibid.

${ }^{3}$ See details below.
} 


\section{Highlights of the 2019 Sustainable Development Goals are:}

The major highlights of the 2019 United Nations Sustainable Development Goals are: No poverty ${ }^{1}$, Zero hunger ${ }^{2}$, Good health and well-being ${ }^{3}$, Quality education ${ }^{4}$, Gender equality ${ }^{5}$, clean water and sanitation ${ }^{6}$, Affordable and clean energy ${ }^{7}$, Decent work and economic growth ${ }^{8}$, Industry, Innovation and Infrastructure ${ }^{9}$, Reduced Inequalities ${ }^{10}$, Sustainable Cities and Communities ${ }^{11}$, Responsible Consumption and Production ${ }^{12}$, Climate Action $^{13}$, Life below Water ${ }^{14}$, Life on Land ${ }^{15}$, Peace, Justice and Strong Institutions ${ }^{16}$ and Partnership for the Goals. ${ }^{17 \mathrm{a}}$

As laudable as the above goals are, African Nations, especially Nigeria, appear yet to take concrete steps to actualizing the 2019 Sustainable Development Goals. For example, it has also been observed, rightly in our opinion that "besides, health-care systems in Africa are not getting better and many members of the affluent population still resort to health tourism with a large chunk of newly trained health experts migrating out of the continent for better opportunities." $1 \mathrm{~b}$ Similarly, "other issues on the SDGs such as gender equality, access to clean water and sanitation, affordable and clean energy, availability of decent work, reduction of inequalities and promotion of human rights, justice and strong institutions are still lagging behind levels obtainable in other jurisdictions." $21 \mathrm{c}$

Although Nigeria has said that it is striving to attain some measure of success, as some of the goals are being prioritized over others. The Senior Special Assistant to the President on SDGs, Mrs. Adejoke Orelope-Adefulire, at a media interactive session in New York on the state of the SDGs in Nigeria said the country has not been "swallowing all the goals and targets hook, line and sinker" but was prioritizing them. This is yet to be seen beyond rhetoric that also marked the failure of MDGs, in this regard. ${ }^{18}$

Similarly it has also been rightly observed that, as an example, the number of out-of-school children in Nigeria is insufferable. Issues of insecurity are worsening and opportunities for employment and decent work are dwindling. If these indicators are not encouraging, where is the glimmer of hope in the attainment of the SDGs, as public officers have claimed? Are there other positives on the improvement of the living conditions of the average Nigerian for example that are not obvious to the public. ${ }^{19}$

General Views of the United Nations Secretary-General on the Sustainable Development Goals Report 2019: The Sustainable Development Goals Report 2019 highlights areas that can drive progress across all 17 SDGs: financing; resilience; sustainable and inclusive economies; more effective institutions; local action; better use of data; and harnessing science, technology and innovation with a greater focus on digital transformation. According to the foreword to the Sustainable Development Goals Report $2019^{20}$ written by: António Guterres SecretaryGeneral of the United Nations, pursuing the goals, over time, has as brought tremendous advantages. In his words: "Since its inception in 2015, the 2030 Agenda has provided a blueprint for shared prosperity in a sustainable world - a world where all people can live productive, vibrant and peaceful lives on a healthy planet. The year 2030 is just over a decade away, and we must ask ourselves if our actions today are laying the right foundation to achieve the Sustainable Development Goals (SDGs). "2I

In summary the Sustainable Development Goals Report 2019 can be said to provide "evidence-based insights to answer this question. He further stated that the report demonstrates that progress is being made in some critical areas, and that some favorable trends are evident. Extreme poverty has declined considerably, the under-5 mortality rate fell by 49 per cent between 2000 and 2017, immunizations have saved millions of lives, and the vast majority of the world's population now has access to electricity." 22 "Countries are taking concrete actions to protect our

\footnotetext{
${ }^{1}$ See the United Nations Sustainable Development Goals Report 2019, page 22

${ }^{2}$ See the United Nations Sustainable Development Goals Report 2019, page 24.

${ }^{3}$ See the United Nations Sustainable Development Goals Report 2019, page 26.

${ }^{4}$ See the United Nations Sustainable Development Goals Report 2019, page 30.

${ }^{5}$ See the United Nations Sustainable Development Goals Report 2019, page 32.

${ }^{6}$ See the United Nations Sustainable Development Goals Report 2019, page 34.

${ }^{7}$ See the United Nations Sustainable Development Goals Report 2019, page 36.

${ }^{8}$ See the United Nations Sustainable Development Goals Report 2019, page 38.

${ }^{9}$ See the United Nations Sustainable Development Goals Report 2019, page 40.

${ }^{10}$ See the United Nations Sustainable Development Goals Report 2019, page 42.

${ }^{11}$ See the United Nations Sustainable Development Goals Report 2019, page 44.

${ }^{12}$ See the United Nations Sustainable Development Goals Report 2019, page 46.

${ }^{13}$ See the United Nations Sustainable Development Goals Report 2019, page 48.

${ }^{14}$ See the United Nations Sustainable Development Goals Report 2019, page 50.

${ }^{15}$ See the United Nations Sustainable Development Goals Report 2019, page 52.

${ }^{16}$ See the United Nations Sustainable Development Goals Report 2019, page 54.

21a See the United Nations Sustainable Development Goals Report 2019, page 56.

$21 \mathrm{~b}$ The Guardian, Nigeria Ibid.

${ }^{21 \mathrm{c}}$ The Guardian, Nigeria Ibid.

${ }^{18}$ The Guardian, Nigeria Ibid.

${ }^{19}$ The Guardian, Nigeria Ibid.

${ }^{20}$ See The United Nations Sustainable Development Goals Report 2019, P. 2.

${ }^{21}$ Ibid.

22 Ibid.
} 
planet: marine protected areas have doubled since 2010; countries are working concertedly to address illegal fishing; 186 parties have ratified the Paris Agreement on climate change, and almost all have communicated their first nationally determined contributions."1a

"Furthermore, about 150 countries have developed national policies to respond to the challenges of rapid urbanization, and 71 countries and the European Union now have more than 300 policies and instruments supporting sustainable consumption and production. A wide range of other actors - international organizations, businesses, local authorities, the scientific community and civil society-have engaged with the SDGs in a manner that generates great hope for the coming decade. The United Nations, for its part, is working hard to reposition to the United Nations development system to be better equipped to meet the needs of governments to respond to this integrated and transformative agenda." $27 \mathrm{~b}$

\section{Disturbing Signals on Deteriorating Environmental Conditions around the Global Environment:}

Notwithstanding that progress, the report identified there are still many areas that need urgent collective attention. In the words of the United Nations-General Secretary:

"....The natural environment is deteriorating at an alarming rate: sea levels are rising; ocean acidification is accelerating; the past four years have been the warmest on record; one million plant and animal species are at risk of extinction; and land degradation continues unchecked. We are also moving too slowly in our efforts to end human suffering and create opportunity for all: our goal to end extreme poverty by 2030 is being jeopardized as we struggle to respond to entrenched deprivation, violent conflicts and vulnerabilities to natural disasters. Global hunger is on the rise, and at least half of the world's population lacks essential health services...."

He continued by stating further that the SDG Summit, the Climate Action Summit and the other crucial meetings which took place in New York in September 2019 provided leaders everywhere with an opportunity to get the world back on track and to kick-start a decade of delivery for people and the planet. The time is right, and that nations and peoples around the world must act now. ${ }^{3}$

\section{Recent Updates from the World Wild Life Fund (WWF):}

A recent report has shown that if the world does not act urgently to address the nature and climate emergency, the world stands to see $\$ 10$ trillion wiped off the global economy over the next 30 years. The report from the World Wild life Fund (WWF) revealed for the first time names of countries whose economies would be worst affected over the next 30 years if the world does not act urgently to address the global environmental crises. ${ }^{4}$

The study, Global futures which circulated the economic cost of nature's decline across 140 countries ranging from India, Brazil, shows that if the world carries on with "business as usual", the US would see the largest losses of annual GDP in absolute terms, with $\$ 83$ billion wiped off its economy each year by 2050 - an amount equivalent to the entire annual GDP of Guatemala. Japan and UK also stood to lose staggering amounts-\$80 billion and \$21 billion every year respectively. In all three cases, this is due largely to expected damage to their coastal infrastructure, agricultural land through increased flooding and erosion as a result of losses of natural coastal defences such as coral reefs and mangroves.

Developing countries are also predicted to be badly affected, with Eastern and Western Africa, central Asia and parts of South America hit particularly hard, as nature loss impacts on production levels, trade and food prices. According to the report, the top three countries predicted to lose the most as a percentage of their GDP are Madagascar, Togo and Vietnam, which by 2050 are expected to respectively see declines of 4.2 per cent, 3.4 per cent and 2.8 per cent per year. ${ }^{5}$

"This ground-breaking study show how conserving nature is not only a moral issue but a social and economic one. Not only will losing nature have a huge impact on human life and livelihoods, it will be catastrophic for world future prosperity. People across the world are already feeling the impact of rising food prices, droughts, commodity shortages, extreme flooding and coastal erosion. Yet for the next generation things will be many times worse, with trillions wiped off world economies by 2050," said Marco Lambertini, Director General of WWF International. ${ }^{6}$ "What is even more alarming is that these are conservative estimates as, at present, only some of the many benefits nature provides us can be modelled. Nor is it possible to take into account the risk-multiplying effects of environmental tipping points, beyond which ecosystems change rapidly and irreversibly, leading to sudden 
catastrophic loss of nature's services. If all of these issues were factored in, the figures would be even starker."1

The Global Futures study used new economic and environmental modelling to assess what the macroeconomic impact would be if the world pursued "business as usual," including widespread and untargeted land-use change, continued increase in emissions of greenhouse gases, and further loss of natural habitats. It found this approach would cost the world at least $\$ 479$ billion a year, adding up to $\$ 9.87$ trillion by 2050 - roughly equivalent to combined economies of the UK, France, India and Brazil. In contrast, under a scenario in which landuse is carefully managed to avoid further loss of areas important for biodiversity and ecosystem services, which the study terms the 'Global Conservation' scenario, economic outcomes would be dramatically better, with global GDP rising by $\$ 4900$ billion per year above the business as usual calculation. ${ }^{2}$

This pioneering method of analysis was created through a partnership between WWF, the Global Trade Analysis Project at Purdue University, and the Natural Capital Project, cofounded by the University of Minnesota. Co-founded of the Natural Capital Project, Steve Polasky said: "The world's economies, businesses and our own well-being all depend on nature. But from climate change, extreme weather and flooding to water shortages, soil erosion and species extinctions evidence shows that our planet is changing faster than at any other time in history. ${ }^{3}$ The way we feed, fuel and finance ourselves is destroying the life-support systems on which we depend, risking global economic devastation." The Global Futures study predicts annual global losses by 2050 of: \$327 billion from damaged protections from flooding, storm surges and erosion due to changes in vegetation along coastlines and sea-level rises $\$ 128$ billion from loss of carbon storage, which protects against climate change. ${ }^{4}$

\section{Conclusion}

This paper analyzed the threats to the realization of the 2019 United Nations Sustainable Development Goals in the light of global changing trends in the global environmental conditions. The paper aligns itself with the alarm of the United Nations Secretary-General on the deteriorations of the natural environments, rising sea levels, accelerating acidification, global warming, increasing land degradations, increasing poverty, conflicts, natural disasters around the globe, and other threats to the survival of mankind in their natural environments and the huge economic losses facing mankind as highlighted in the World Wild life Fund (WWF) from recent findings. The above calls for an urgent and sustained global action to wave-off the coming disasters on the nations of the world. It is on the above that we make the following recommendations.

\section{RECOMMENDATIONS}

1. From the United Nations Sustainable Development Goals Report 2019 and the World Wild Life Fund (WWF) recent report, it is abundantly clear that deeper, faster and more ambitious responses are needed to unleash the social, environmental and economic transformations needed to achieve the $2030 \mathrm{UN}$ sustainable goals.

2. In line with the United Nations Sustainable Development Goals Report 2019, this paper aligns with the views of the United Nations Secretary-General that, "in everything we do, we must diligently ensure that policy choices leave no one behind, and that national efforts are supported by effective international cooperation, grounded in a commitment to diplomacy and crisis prevention." 5

3. Again, this paper subscribes to the view of the Guardian, Nigeria to the effect that "the role of political leaders, particularly in Africa in enhancing the attainment of the SDGs appears not too reassuring. And this is where Nigeria's leadership is a desideratum. Issues of extreme poverty as still prevalent in Africa. The SDG's aim at eliminating extreme poverty by 2030 appears far-fetched in Africa, particularly in Nigeria, which just overtook India as the poverty capital of the world. This is akin to the second goal of the SDGs, which aims at ending hunger completely by 2030, since a sizeable proportion of the African population go to bed hungry daily." 6

4. Though the narrative from the government on the performance of the SDGs in Nigeria appears positive, it should not be unexpected, since government officials all over the world always "blow their own trumpet." Indicators of the seemingly worsening conditions of living standards across the country, which is what the SDGs are meant to address, tell a different story. ${ }^{7}$

5. The "year 2030 is merely 11 years away and governments and other political leaders in Nigeria and across the continents should avoid a situation where most of the countries on the continent would fall short of attaining the SDGs, as was the case for the MDGs." 8

Ibid.

${ }^{4}$ Ibid.

5 The Guardian, Nigeria Ibid.

${ }^{6}$ The Guardian, Nigeria Ibid.

${ }^{7}$ The Guardian, Nigeria Ibid.

${ }^{8}$ The Guardian, Nigeria Ibid.
} 